\title{
Effects of sodium bicarbonate as an inorganic carbon source on the growth of scenedesmus dimorphus
}

무기탄소원으로서의 $\mathrm{NaHCO}_{3}$ 가 미세조류 Scenedesmus dimorphus의 성장에 미치는 영향 평가

\author{
Sung-Jin Joo $\cdot$ SHAN ZHANG · Kyoung Jin Choi · SeokMin Lee · Sun-Jin Hwang* \\ 주성진 · 장산 · 최경진 · 이석민 · 황선진
}

Department of Environmental Engineering, Kyung Hee University

경희대학교 환경공학과

\begin{abstract}
This study investigates the effect of sodium bicarbonate $\left(\mathrm{NaHCO}_{3}\right)$ on growth of $\mathrm{S}$. dimorphus. $\mathrm{NaHCO}_{3} \mathrm{Concentra-}$ tion was varied from 0 to $2 \mathrm{~g}-\mathrm{C} / \mathrm{L}$. As a result, the increase in concentration of $\mathrm{NaHCO}_{3}$ up to $1.5 \mathrm{~g}-\mathrm{C} / \mathrm{L}$ increased dry weight of algae. The highest specific growth rate of $S$. dimorphus was 0.36 day ${ }^{-1}$ which was obtained at concentration of $0.5 \mathrm{~g}-\mathrm{C} / \mathrm{L} \mathrm{NaHCO}$. $\mathrm{pH}$ showed a large variation range at the concentrations lower than $0.5 \mathrm{~g}-\mathrm{C} / \mathrm{L} \mathrm{NaHCO}$ whereas inorganic carbon, nitrate and phosphorus removal rates were almost same at the concentrations higher than $0.5 \mathrm{~g}-\mathrm{C} / \mathrm{L} \mathrm{NaHCO} \mathrm{N}_{3}(0.75,1,1.25,1.5,2 \mathrm{~g}-\mathrm{C} / \mathrm{L}$ $\mathrm{NaHCO}_{3}$ ). Their average inorganic carbon, nitrate and phosphorus removal rate were $70 \mathrm{mg}-\mathrm{C} / \mathrm{L} / \mathrm{d}, 11.3 \mathrm{mg}-\mathrm{N} / \mathrm{L} / \mathrm{d}$, and 1.6 $\mathrm{mg}-\mathrm{P} / \mathrm{L} / \mathrm{d}$, respectively. Thus, $\mathrm{NaHCO}_{3}$ didn't effect on inorganic carbon, nitrate and phosphorus removal rate of $S$. dimorphus.
\end{abstract}

Key words : Microalgae, Scenedesmus dimorphus, Sodium bicarbonate, Inorganic carbon source, Specific growth rate 주제어 : 미세조류, 세네데스무스 디모르푸스, 탄산수소나트륨, 무기탄소원, 비성장속도

\section{1. 서 론}

미세조류는 수중에 서식하며 광합성을 통해 산 소를 생산하는 단세포 생물로써, 지구 전체의 광 합성량의 절반을 미세조류가 담당하고 있다 $(\mathrm{Ru}-$ bio et al., 2003). 이러한 미세조류는 대사를 진 행하면서 pigments, polyunsaturated fatty acids(PUFAs), tryglycerides(TAGs) 등의 유용 물질을 생산할 수 있어 식품, 의약품, 바이오연료 생산분야 등 다방면에서 이용 가능한 생물자원이 다(Apt and Behrens 1999; Singh et al. 2005; Berge and Barnathan 2005; Chisti 2007; Han et al. 1999).

- Received 19 August 2014, revised 06 October 2014, accepted 10 October 2014.

*Corresponding author. Tel : +82-31-201-2497 Fax : +82-31-203-4589 E-mail : sjhwang@khu.ac,kr
탄소원으로 용존 무기탄소를 이용하는 독립영 양 미세조류(autotrophic microalgae)는 대기 중의 $\mathrm{CO}_{2}$ 가스로부터 생성된 $\mathrm{CO}_{2}(\mathrm{aq}), \mathrm{HCO}_{3}{ }^{-}$ (aq) 형태의 무기탄소를 이용해 대사를 진행할 수 있지만, 대기 중 $\mathrm{CO}_{2}$ 농도가 $0.03 \%$ 로 낮아 최 대성장 및 높은 생산성을 유지하는데 필요한 무 기탄소는 공기 폭기 만으로는 부족하다(Becker, 1994).

이에 따라 충분한 $\mathrm{CO}_{2}$ 공급을 위한 연구가 발 전시설 등으로부터의 배기가스를 이용하는데 초 점을 맞추어 진행되고 있으나(Tsuzuki et al. 1990; Chu et al. 1996), 방대한 양의 $\mathrm{CO}_{2}$ 를 고 정하기 위한 기술이 아직 정착되지 않고 있으며, 이를 저장하였다가 사용하기 위해서는 $150 \mathrm{~atm}$ 의 높은 압력이 필요하므로 많은 비용이 발생하게 
된다(Zhanyou, 2011).

이러한 점들을 고려할 때, 소규모 장치의 경 우 $\mathrm{NaHCO}_{3}$ 를 무기탄소원으로 이용하여 용액 에 용해시켜 공급하면, $\mathrm{NaHCO}_{3}$ 가 $\mathrm{CO}_{2}$ 보다 용 해도가 높아 수용액에 내에서 고농도로 잔존하 므로, 대기 중으로 손실되는 $\mathrm{CO}_{2}$ 양을 최소화하 면서 무기탄소를 안정적으로 공급할 수 있는데 (Hsueh et al. 2007), 이는 대기압에서도 가능 하기 때문에 높은 압력이 불필요하고, 저장 및 운송이 용이하여 비용을 크게 절감할 수 있다. 또한, 무기탄소의 공급 이외에도 bicarbonate 는 용액 중에서 완충작용이 있어 일정 $\mathrm{pH}$ 를 유 지할 수 있는 장점도 있다.

Bicarbonate는 미세조류 종 마다 그 대사효 율이 다르고, bicarbonate 이용에 따라 조류의 생화학적 구성성분이 다소 바뀔 수도 있는 것으 로 보고되었다(Giordano et al. 2005). 즉, 과 도한 bicarbonate의 공급은 성장, 광합성, 질소 의 이용에 있어 부정적 영향을 야기할 수 있는 것 으로 나타났다(White et al. 2011).

담수성 미세조류인 Scenedesmus dimorphus는 녹조류에 속하는 단세포 미세조류로써 $2,4,8$ 또는 16 개의 세포가 군체를 형성하며 성 장하며, 탄수화물과 지질의 함량이 높아 바이오 연료 추출을 위한 생물자원으로 사용될 수 있다 (Mata et al. 2010).

이상과 같은 배경 하에, 본 연구에서는 바이 오연료 추출을 위한 자원으로서 미세조류인 $S$. dimorphus의 대량배양을 위해, $\mathrm{NaHCO}_{3}$ 주입 을 통한 대량배양시의 적정 농도를 도출하고자, $0 \sim 2 \mathrm{~g}-\mathrm{C} / \mathrm{L}$ 의 조건에서 미세조류 성장량 및 질소, 인, 무기탄소 소비속도 등의 기본적인 특 성을 파악하는 것을 목표로 연구를 진행하였다.

\section{2. 실험방법}

\section{1 사용 균주 및 배지}

본 연구에 사용된 미세조류는 S. dimorphus로 KORDI(Korea Ocean Research \&
Development Institute)으로부터 분양받았으 며, 배양을 위해 사용한 배지는 Bold's Basal Medium(BBM)으로 조성은 Table. 1과 같다.

Table 1. Composition of Bold's Basal medium

\begin{tabular}{|c|c|c|}
\hline \multicolumn{3}{|c|}{ Bold's Basal Medium } \\
\hline Ingredient & Concentration & Dosage \\
\hline $\mathrm{NaNO}_{3}$ & $25 \mathrm{~g} / \mathrm{L}$ & $10 \mathrm{ml}$ \\
\hline $\mathrm{MgSO}_{4} \cdot 7 \mathrm{H}_{2} \mathrm{O}$ & $7.5 \mathrm{~g} / \mathrm{L}$ & $10 \mathrm{ml}$ \\
\hline $\mathrm{NaCl}$ & $2.5 \mathrm{~g} / \mathrm{L}$ & $10 \mathrm{ml}$ \\
\hline $\mathrm{K}_{2} \mathrm{HPO}_{4}$ & $7.5 \mathrm{~g} / \mathrm{L}$ & $10 \mathrm{ml}$ \\
\hline $\mathrm{KH}_{2} \mathrm{PO}_{4}$ & $17.5 \mathrm{~g} / \mathrm{L}$ & $10 \mathrm{ml}$ \\
\hline $\mathrm{CaCl}_{2} \cdot 2 \mathrm{H}_{2} \mathrm{O}$ & $2.5 \mathrm{~g} / \mathrm{L}$ & $10 \mathrm{ml}$ \\
\hline $\mathrm{H}_{3} \mathrm{BO}_{3}$ & $11.4 \mathrm{~g} / \mathrm{L}$ & $1 \mathrm{ml}$ \\
\hline \multicolumn{2}{|c|}{ Trace } & $1 \mathrm{ml}$ \\
\hline $\mathrm{ZnSO}_{4} \cdot 7 \mathrm{H}_{2} \mathrm{O}$ & $8.82 \mathrm{~g}$ & \\
\hline $\mathrm{MnCl}_{2} \cdot 4 \mathrm{H}_{2} \mathrm{O}$ & $1.44 \mathrm{~g}$ & \\
\hline $\mathrm{CuSO}_{4} \cdot 5 \mathrm{H}_{2} \mathrm{O}$ & $1.57 \mathrm{~g}$ & \\
\hline $\mathrm{Co}\left(\mathrm{NO}_{3}\right)_{2} \cdot 6 \mathrm{H}_{2} \mathrm{O}$ & $0.49 \mathrm{~g}$ & \\
\hline $\mathrm{MoO}_{3}$ & $0.71 \mathrm{~g}$ & \\
\hline \multicolumn{2}{|c|}{ EDTA-KOH solution } & $1 \mathrm{ml}$ \\
\hline EDTANa $_{2}$ & $5.0 \mathrm{~g}$ & \\
\hline $\mathrm{KOH}$ & $3.1 \mathrm{~g}$ & \\
\hline Distilled water & $100 \mathrm{ml}$ & \\
\hline \multicolumn{2}{|c|}{ Fe solution } & $1 \mathrm{ml}$ \\
\hline $\mathrm{FeSO}_{4} \cdot 7 \mathrm{H}_{2} \mathrm{O}$ & $4.98 \mathrm{~g}$ & \\
\hline Conc. $\mathrm{H}_{2} \mathrm{SO}_{4}$ & $1 \mathrm{ml}$ & \\
\hline Distilled water & $1 \mathrm{~L}$ & \\
\hline \multicolumn{2}{|c|}{ Distilled water } & $1 \mathrm{~L}$ \\
\hline
\end{tabular}

\section{2 미세조류 배양}

분양받은 미세조류는 Table. 1 과 같이 조성된 $\mathrm{BBM}$ 배지와 혼합하여 0.2 OD(Optical Density)가 되도록 조정한 다음, $250 \mathrm{~mL}$ cell culture flask를 이용하여, 온도 $25^{\circ} \mathrm{C} \pm 1, \mathrm{PPFD}$ (Photosynthetic photon flux density) 100 $\mu \mathrm{mol} / \mathrm{m}^{2} / \mathrm{sec}$ 인 항온 광배양기(Multi-thermo chamber, HB-305M)에서 20일간 계대배양을 실시하여 $1.5 \mathrm{OD}$ 까지 배양 후 실험에 사용하였 다. 


\section{3 실험 방법}

본 실험을 위한 배지는 질소 $100 \mathrm{mg}-\mathrm{N} / \mathrm{L}$ 및 인 $10 \mathrm{mg}-\mathrm{P} / \mathrm{L}$ 농도로 설정한 modified $\mathrm{BBM}$ 을 제조하여 이용하였으며, 무기탄소 농 도는 다양하게 0 (control), 0.05, 0.1, 0.25, $0.5,0.75,1,1.25,1.5,2 \mathrm{~g}-\mathrm{C} / \mathrm{L}$ 로 설정하여 $\mathrm{NaHCO}_{3}$ 를 주입하였다. 실험을 위한 반응조는 $1 \mathrm{~L}$ 삼각플라스크를 이용하여 운전용량 $500 \mathrm{ml}$ 로 진행하였다.

미세조류의 초기 접종농도는 $0.2 \mathrm{OD}$ 로 접종 해 주었으며, 고른 광조사와 혼합을 위해서 회 전식 진탕기를 이용하여 $150 \mathrm{rpm}$ 으로 교반하였 다. 운전온도를 $25 \pm 3^{\circ} \mathrm{C}$ 로 설정해 항온조에서 운전하였고, 운전 초기 $\mathrm{pH}$ 는 $9.5 \pm 0.5$ 로 설정 하였으며, $0.5 \mathrm{~N} \mathrm{HCl}$ 과 $0.5 \mathrm{~N} \mathrm{NaOH}$ 을 이용하 여 24시간 간격으로 조절해 주었다.

광 조사는 $\mathrm{LED}$ 를 이용하여 white 파장으로 조사해 주었다. 광도는 UV 광도계(LI-1400, $\mathrm{LI}-\mathrm{COR}$ )를 사용하여 측정하였으며, 광도는 80 $\mu \mathrm{mol} / \mathrm{m}^{2} / \mathrm{s}$ 로 유지해 주었다. 또한, 광조사 주 기는 24 시간 연속으로 실시하였으며, 반응조는 batch test 형태로 5일 동안 운전하였다.

\section{4 분석방법}

미세조류 성장량은 Standard method에 명 시된 $\mathrm{SS}$ 측정방법을 이용한 dry weight과 $\mathrm{OD}$ 를 측정하여 평가하였으며, OD는 spectrophotometer (Optizen POP, Mecasys Co., Korea)를 이용하여 $660 \mathrm{~nm}$ 에서의 흡광도를 측 정하여 정해졌다. $\mathrm{NO}_{3}-\mathrm{N}$ 과 $\mathrm{PO}_{4}-\mathrm{P}$ 는 수질분 석 kit법을 이용하여 water analyzer(model HS-3300, HUMAS Inc.)로 분석하였으며, IC(inorganic carbon)는 Total Organic Carbon Analyzer(TOC-Vcsn, Shimadzu, Ja$\mathrm{pan})$ 를 이용하여 분석하였다.

미세조류의 비증식 속도(Specific Growth Rate, SGR, $\mu$ )는 아래의 Eq-(1)을 이용하여 계산하였다(Kwon et al., 2012).

$$
\mu=\ln \left(\mathrm{X}-\mathrm{X}_{0}\right) /\left(\mathrm{T}-\mathrm{T}_{0}\right) \quad \mathrm{Eq}-(1)
$$

여기서, $\mathrm{X}$ 는 시간 $\mathrm{T}(\mathrm{day})$ 에서의 미세조류 건 조중량이고, $\mathrm{X}_{0}$ 는 시간 $\mathrm{T}_{0}$ (day)에서의 미세조류 건조중량이다.

\section{3. 결과 및 고찰}

\section{$3.1 \mathrm{NaHCO}_{3}$ 의 농도에 따른 성장량 변화}

$\mathrm{NaHCO}_{3}$ 주입 농도에 따른 $S$. dimorphus의 성장량 변화 Fig. 1과 최대 성장량 및 specific growth rate를 Fig. 2에 나타내었다. $\mathrm{NaHCO}_{3}$ 주입량이 $1.5 \mathrm{~g}-\mathrm{C} /$ 까지는 주입량이 증가할수록 미세조류의 성장량도 증가하는 경향을 나타났으 나, $2 \mathrm{~g}-\mathrm{C} / \mathrm{L}$ 에서는 다소 감소하는 것으로 나 타났다.

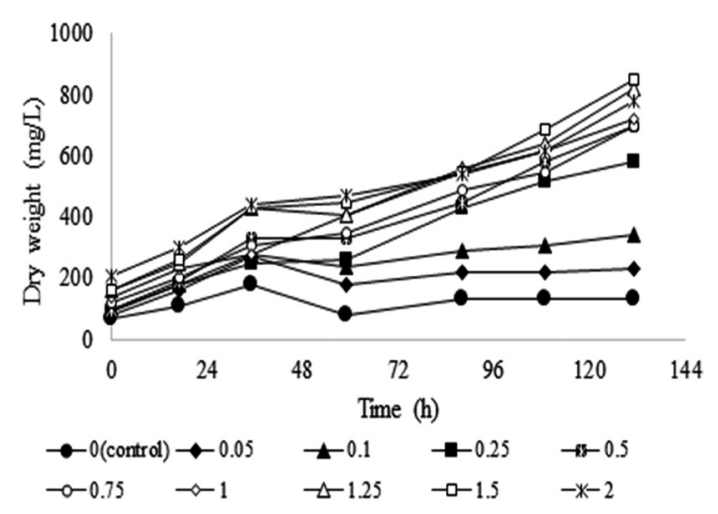

Fig. 1. S. dimorphus growth according to the $\mathrm{NaHCO}_{3}$ conc.

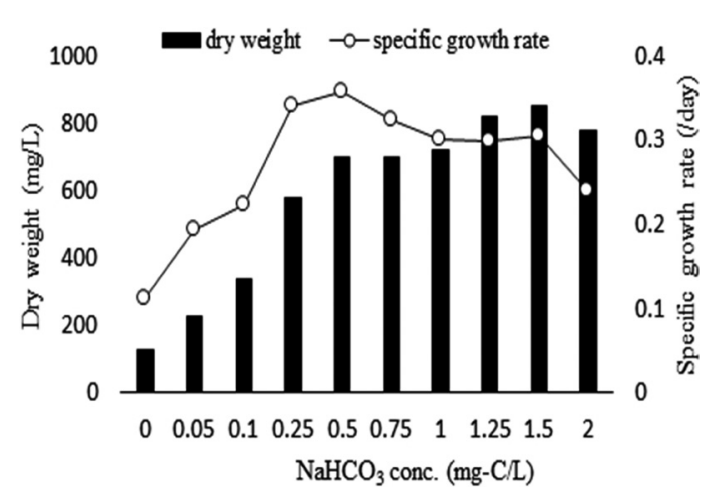

Fig. 2. Maximum dry weight and growth rate according to the $\mathrm{NaHCO}_{3}$ conc. 
$\mathrm{NaHCO}_{3}$ 주입량이 $0 \sim 0.1 \mathrm{~g}-\mathrm{C} / \mathrm{L}$ 인 조건 에서는 운전초기에 미세조류의 성장이 멈춘 것 으로 나타났는데, 이는 대사에 필요한 무기탄소 가 고갈됨에 따라서 광합성 대사를 진행하지 못 한 것이 원인으로 판단되었다. 일반적으로 독립 영양 미세조류는 $\mathrm{Eq}-(2)$ 와 같이 수중에 용해된 $\mathrm{HCO}_{3}{ }^{-}$형태의 무기탄소를 이용하여 광합성 대 사를 진행한 후 biomass를 생성한다(Borowitzka, 1998; Chevalier et al., 2000).

$$
\begin{aligned}
& \mathrm{H}_{2} \mathrm{O}+\underset{\mathrm{HCO}_{3}^{-} \rightarrow}{\mathrm{C}(\text { biomass })}+1 / 2 \mathrm{O}_{2}+3 \mathrm{OH}^{-}
\end{aligned}
$$

$\mathrm{SGR}$ 의 경우 $0.5 \mathrm{~g}-\mathrm{C} / \mathrm{L}$ 조건에서 0.36 /day 로 가장 높게 나타났으며, 그 이후부터는 점차 감소하는 경향을 보였다. Zhao(2012)의 연구에 의하면, Scenedesmus qudricauda를 이용하 여 $\mathrm{NaHCO}_{3}$ 의 농도를 $0 \sim 0.01 \mathrm{~mol} / \mathrm{L}$ 로 설정 하여 배양시, $\mathrm{NaHCO}_{3}$ 의 농도가 높을수록 $\mathrm{SGR}$ 이 감소하는 경향이 나타나는 등 본 실험과 유 사한 결과를 얻었다고 보고되고 있다. 이에 대한 원인으로 Carvalho and Malcata (2005)에 따 르면, 미세조류는 종 마다 무기탄소의 농도에 따 라서 SGR 값은 유의적인 차이를 나타낼 수 있으 며, 이는 곧 성장에 영향을 줄 수 있는 무기탄소 의 농도가 다르기 때문인 것으로 보고되고 있다.

\section{2 $\mathrm{NaHCO}_{3}$ 농도에 따른 $\mathrm{pH}$ 와 IC 변화}

Fig. 3에 $\mathrm{NaHCO}_{3}$ 공급 농도에 따른 $\mathrm{pH}$ 변화 를 나타내었다. $\mathrm{NaHCO}_{3}$ 주입 농도가 낮을수록 $\mathrm{pH}$ 는 급격히 증가하는 경향을 나타내었고, 주입 농도가 높아질수록 $\mathrm{pH}$ 변화 폭은 좁게 나타났 다. 이는 $\mathrm{NaHCO}_{3}$ 의 주입 농도가 높을수록 완충 능이 커지기 때문인데, 일반적으로 미세조류는 대사의 형태나 질소원의 종류에 따라서도 $\mathrm{pH}$ 는 다소 다르게 나타날 수 있다. 또한, $\mathrm{Eq}-(2)$ 와 같 이 photoautotrophic 미세조류의 경우, 광합성 대사를 진행하는 과정에서 $\mathrm{OH}^{-}$를 생성하기 때 문에 $\mathrm{pH}$ 가 증가하며, $\mathrm{Eq}-(3)$ 과 같은 반응에 의
해 미세조류가 섭취하는 질소원의 형태가 $\mathrm{NO}_{3}{ }^{-}$ 일 경우 $\mathrm{pH}$ 가 증가할 수 있다.

$$
\begin{array}{r}
106 \mathrm{CO}_{2}+138 \mathrm{H}_{2} \mathrm{O}+16 \mathrm{NO}_{3}^{-} \rightarrow \mathrm{Eq}-(3) \\
\left(\mathrm{CH}_{2} \mathrm{O}\right)_{106}\left(\mathrm{NH}_{3}\right)_{16}+16 \mathrm{OH}^{-}+138 \mathrm{O}_{2}
\end{array}
$$

Fig. 4에 $\mathrm{NaHCO}_{3}$ 주입농도에 따른 잔여 $\mathrm{IC}$ 변화를 나타내었다. 잔여 IC 농도는 초기 농도 $0.5 \mathrm{~g}-\mathrm{C} / \mathrm{L}$ 이상인 모든 조건에서 약 70 $\mathrm{mg}-\mathrm{C} / \mathrm{L} / \mathrm{d}$ 의 속도로 소비되는 것으로 나타나, $\mathrm{NaHCO}_{3}$ 의 주입농도에 따른 차이가 거의 없는 것으로 판단된다.

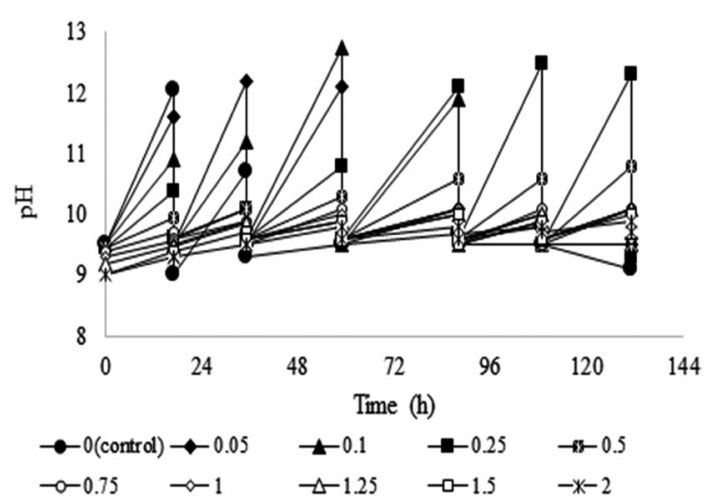

Fig. 3. Variation of $\mathrm{pH}$ according to the $\mathrm{NaHCO}_{3}$ conc.

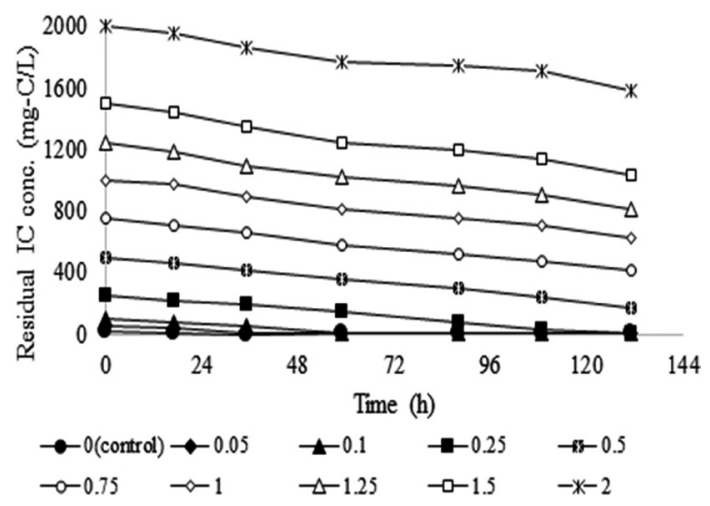

Fig. 4. Variation of residual IC conc. according to the $\mathrm{NaHCO}_{3}$ conc. 


\section{3 $\mathrm{NaHCO}_{3}$ 의 농도에 따른 질소와 인 변화}

Fig. 5와 Fig. 6에 $\mathrm{NaHCO}_{3}$ 주입농도에 따른 잔여 질산성 질소와 인산염의 농도를 나타내었 다. 초기 $\mathrm{NaHCO}_{3}$ 의 농도가 낮을수록 잔여 질 소와 인의 농도는 높게 나타났는데, 이는 무기 탄소의 고갈로 인해서 $S$. dimorphus의 대사가 진행될 수 없기 때문인 것으로 판단된다. 초기 $\mathrm{NaHCO}_{3} 0.5 \mathrm{~g}-\mathrm{C} / \mathrm{L}$ 이상의 모든 조건에서 평 균적으로 질소 $11.3 \mathrm{mg}-\mathrm{N} / \mathrm{L} / \mathrm{d}$, 인 $1.6 \mathrm{mg}-$ $\mathrm{P} / \mathrm{L} / \mathrm{d}$ 의 속도로 소비된 것으로 나타났다.

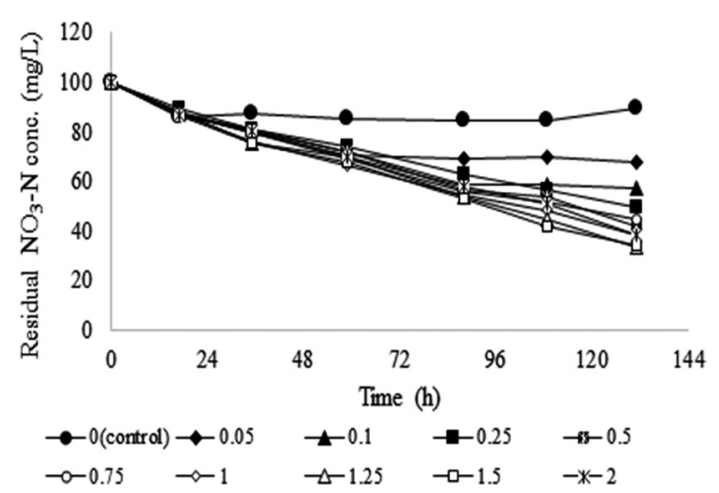

Fig. 5. Variation of residual $\mathrm{NO}_{3}-\mathrm{N}$ conc. according to $\mathrm{NaHCO}_{3}$ conc.

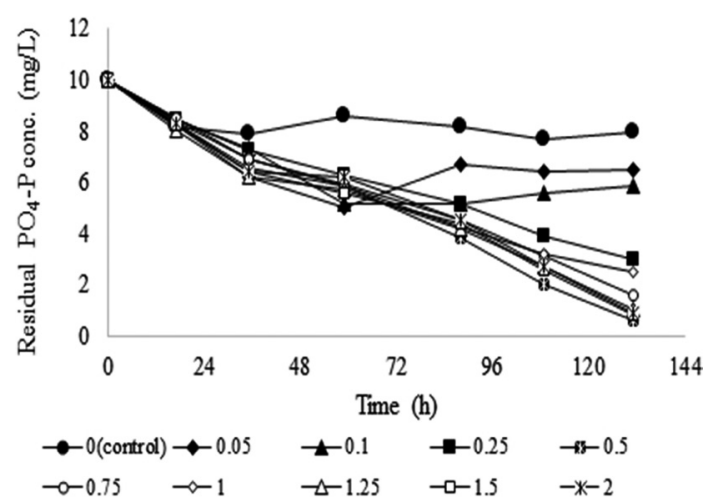

Fig. 6. Variation of residual $\mathrm{PO}_{4}-\mathrm{P}$ conc. according to $\mathrm{NaHCO}_{3}$ conc.

\section{4. 결 론}

본 연구에서는 미세조류 $S$. dimorphus의 배 양을 위해 무기탄소원으로 $\mathrm{NaHCO}_{3}$ 의 주입시 주입농도에 따른 성장 특성을 파악하여 대량배 양을 위한 적정 $\mathrm{NaHCO}_{3}$ 주입농도를 도출하기 위한 기초연구을 수행하였으며, 그 결과는 다음 과 같다.

$\mathrm{NaHCO}_{3} \mathrm{O} \sim 2 \mathrm{~g}-\mathrm{C} / \mathrm{L}$ 의 조건에서 $S . d i-$ morphus를 배양한 결과, $\mathrm{NaHCO}_{3}$ 주입농도 1.5 $\mathrm{g}-\mathrm{C} / \mathrm{L}$ 까지 dry weight는 비례적으로 증가하였 으며, 이 구간에서 비성장속도는 $0.5 \mathrm{~g}-\mathrm{C} / \mathrm{L}$ 조 건에서 $0.36 \mathrm{day}^{-1}$ 로 가장 높게 나타났다.

$\mathrm{pH}$ 는 $\mathrm{NaHCO}_{3}$ 의 주입농도가 높을수록 완충 능의 영향으로 그 변화 폭이 작은 것으로 나타 났다. $\mathrm{IC}, \mathrm{NO}_{3}-\mathrm{N}$ 및 $\mathrm{PO}_{4}-\mathrm{P}$ 는 특정 농도 이상 에서는 $\mathrm{NaHCO}_{3}$ 주입농도에 따른 유의한 영향 을 거의 받지 않는 것으로 나타났으며, 본 연구 에서는 $0.5 \mathrm{~g}-\mathrm{C} / \mathrm{L}$ 이상인 모든 조건에서 각각 약 $70 \mathrm{mg}-\mathrm{C} / \mathrm{L} / \mathrm{d}$, 약 $11.3 \mathrm{mg}-\mathrm{N} / \mathrm{L} / \mathrm{d}$ 및 약 $1.6 \mathrm{mg}-\mathrm{P} / \mathrm{L} / \mathrm{d}$ 의 속도로 소비되는 것으로 나 타났다.

따라서, S. dimorphus의 대량배양을 위한 적 정 $\mathrm{NaHCO}_{3}$ 의 주입농도는 비성장 속도(SGR)를 고려할 경우 $0.5 \mathrm{~g}-\mathrm{C} / \mathrm{L}$ 가 본 연구에서는 가장 최적인 것으로 판단되며, 무기탄소 주입조건 이 외에 빛, 온도, $\mathrm{pH}$ 등의 주요 성장조건을 고려 하여 배양한다면 보다 높은 성장량을 기대할 수 있을 것으로 사료된다.

\section{사 사}

이 논문은 2013년도 정부(교육과학기술부) 의 재원으로 한국연구재단의 기초연구사업 지 원을 받아 수행된 연구입니다. (NRF-20110023132) 


\section{References}

Apt K.E., Behrens P.W. (1999) Commercial developments in microalgal biotechnology, $J$ Phycol, 35, pp. $215-226$

Becker, E.W. (1994) Microalgae, Biotechnology and microbiology, 12, Cambridge, Cambridge University press.

Berge J-P, Barnathan G (2005) Fatty acids from lipids of marine organisms: molecular biodiversity, roles as biomarkers, biologically active compounds, and economical aspects. Adavaces in biochemical engineering/biotechnology, pp.49-125, Springer, Berlin.

Borowitzka, M.A. (1998) Wastewater treatment with algae. pp.203-206, Springer Verlag. Berlin.

Carvalho, A. P., Malcata, F. X. (2005) "Optimization of omega-3 fatty acid production by microalgae : crossover effects of $\mathrm{CO} 2$ and light intensity under batch and continuous cultivation modes", Biotechnol, 7, pp.381388.

Chevalier, P., Proulx, D., Lessard, P., Vincent, W.F., de la Noüe, J., (2000) Nitrogen and phosphorus removal by high latitude matforming cyanobacteria for potential use in tertiary wastewater treatment, $J$ Appl Phycol, 12, pp.105-112.

Chisti Y (2007) Biodiesel from microalgae, Biotechnol adv, 25, pp.294-306.

Chu W.L., Phang S.M., Goh S.H. (1996) Environmental effects on growth and biochemical composition of Nitzchia inconspicua Grunow, J Appl Phycol, 8, pp.389-396.

Giordano M, Beardall J, Raven J (2005) $\mathrm{CO}_{2}$ concentrating mechanisms in algae: mechanisms, environmental modulation, and evolution. Annu Rev Plant Biol, 56, pp. $99-131$.

Han, Y.H., Lee, J.S., Kwak, J.K., Lee, E.H., Cho, M.G., (1999). High-density cultivation of microalgae using microencapsulation. Journal of Korea Fisheries and Aquatic Sciences. 32(2), pp.186-191.
Hsueh H.T, Chu H, Yu S.T. (2007) A batch study on the biofixation of carbon dioxide in the absorbed solution from a chemical wet scrubber by hot spring and marine algae. Chemosphere, 66, pp.878-886.

Kwon, S. H., Lee, E. M., Cho, D. C. (2012) Optimal culturing and enhancement of lipid accumulation in a microalga Botryococcus braunii, Journal of Korean Environmental Sciences, 21(7), pp.779-785.

Mata T.M, Martins A.A., Caetano N.S. (2010) Microalgae for biodiesel production and other applications: a review. Renew Sust Energ. Rev, 14, pp. $217-232$.

Rubio, F.C., Camacho, F.G., Sevilla, J.M., Chisti, Y., Grima, E.M. (2003) A mechanistic model of photosynthesis in microalgae, biotechnology and bioengineering; 81(4), pp. 459-473.

Singh S, Kate B.N., Banerjee U.C. (2005) Bioactive compounds from cyanobacteria and microalgae; an overview, Crit Rev Biotechnol, 25, pp.73-95

Tsuzuki M, Ohnuma E, Sato N, Takaku T, Kawaguchi A (1990) Effects of CO2 concentration during growth on fatty acid composition in microalgae, Plant Physiol, 93, pp. 851-856.

White, D.A. Pagarette, A.Rooks, P. Ali, S.T. (2013) the effect of sodium bicarbonate supplementation on growth and biochemical composition of marine microalgae cultures, J Appl Phycol, 25, pp.153-165.

Zhanyou Chi, James V O'allon and Shulin Chen (2011) Biocarbonate produced from carbon capture for algae culture, 29, Trends in biotechnology. Cell press.

Zhao, G., Yu, J., Jiang, F., Zhang, X., Tan, T. (2012) The effect of differnet trophic modes on lipid accumlation of scenedesmus quadricauda. Bioresource technology, 114, pp. 466-471. 